\title{
A System for Controlling Water Potential in Seed Germination Research
}

\author{
Phil S. Allen ${ }^{1}$, Donald B. White, Karl Russer, and Dave Olson \\ Department of Horticultural Science, University of Minnesota, St. Paul, \\ MN 55108
}

Additional index words. humidity control, saturated salt solutions, seed moisture, temperature control

\begin{abstract}
An inexpensive system for maintaining desired water potentials throughout seed germination was developed. During hydration, a water reservoir at the base of inclined petri dishes allowed continual saturation of filter paper on which seeds were placed. During dehydration, seeds were exposed to equilibrium vapor pressures above saturated salt solutions. Constant temperature, necessary to prevent condensation of water vapor, was achieved via a small $(0.2 \mathrm{~A})$ fan that furnished and circulated heat throughout an insulated chamber in which salt solutions were placed. By operating the chamber above ambient laboratory temperature, interior cooling was not required. The system allowed manipulation of the rate, degree, and frequency of dehydration episodes to which germinating seeds were exposed.
\end{abstract}

Many seeds germinate within the upper few millimeters of the soil surface, where wide moisture fluctuations occur (Rose, 1968). Seeds planted in this region may undergo several periods of hydration followed by dehydration before radicle emergence (Hegarty, 1977).

Even in the laboratory, hydration and dehydration of seeds are difficult to regulate experimentally. For example, seeds are often germinated on moist filter paper in covered petri dishes (Association of Official Seed

Received for publication 17 May 1991. Accepted for publication 27 Dec. 1991. Paper no. 19,096 of the Scientific Journal Series, Univ. of Minnesota Agricultural Experiment Station. The cost of publishing this paper was defrayed in part by the payment of page charges. Under postal regulations, this paper therefore must be hereby marked advertisement solely to indicate this fact.

${ }^{1}$ Current address: Dept. of Agronomy and Horticulture, Brigham Young Univ., Provo, UT 84602.
Analysts, 1989). In this system, water that evaporates or enters seeds via imbibition is removed from the filter paper, resulting in a decreased moisture supply to seeds. Frequent remoistening of blotters may be necessary before radicle emergence. In this case, seeds can experience several unregulated moisture fluctuations before germination. Attempting to avoid such fluctuations by initially adding an excess of water to petri dishes can hamper germination by restricting $\mathrm{O}_{2}$ diffusion to the seeds (Dasberg and Mendel, 1971)

Control of seed moisture loss during dehydration (e.g., imposing water stress treatments) is also difficult. Air-drying is often used to achieve dehydration. The rate and degree of moisture loss, however, are strongly affected by temperature and humidity. Unless these factors are regulated, control of dehydration of air-drying is not possible.

To some extent, drought stress during germination can be simulated by placing seeds 


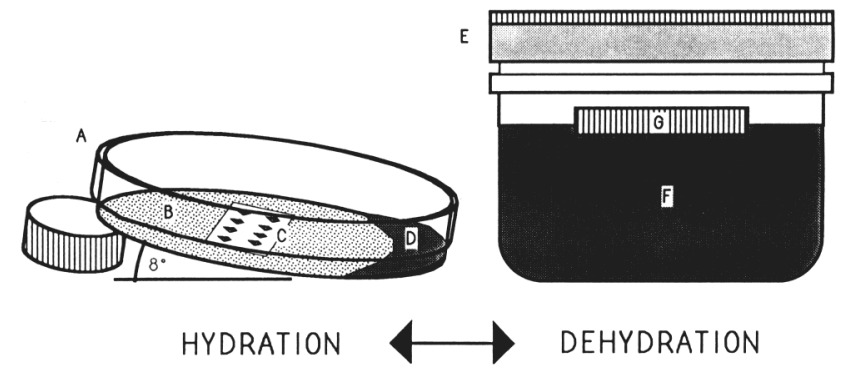

Fig. 1. System for controlling seed moisture fluctuations. Hydration phase: (A) inclined petri dish, (B) moist filter paper, (C) seeds on removable tissue strip, (D) water reservoir. Dehydration phase: (E) sealed jar, (F) saturated salt solution, (G) plastic lid for floating seeds above solution in exposure to equilibrium vapor pressure (relative humidity) that determines water potential during dehydration.

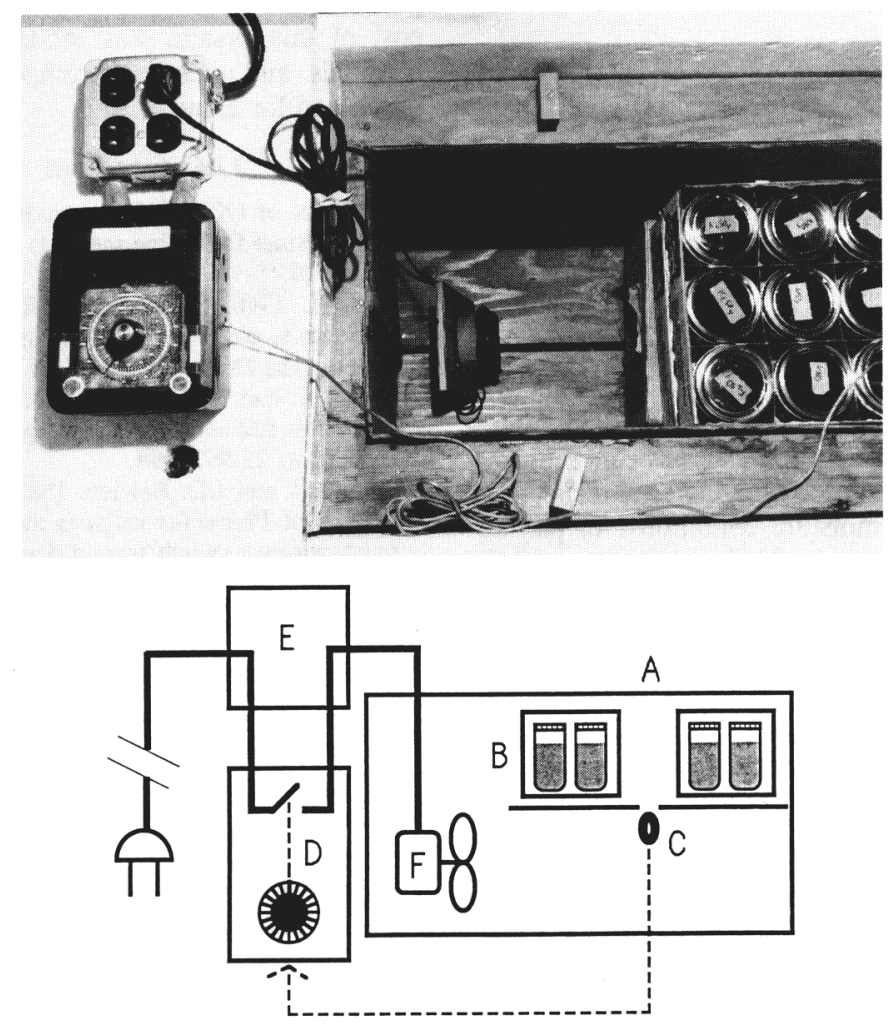

Fig. 2. Photograph (top) and schematic (bottom) of temperature control chamber for high humidity research. (A) chamber box, (B) elevated jars containing saturated salt solutions, (C) temperature sensing thermistor, (D) controller and electrical relay, (E) outlet and junction box, (F) fan.

in solutions of polyethylene glycol (PEG) (Hadas, 1977). In general, such studies are limited to osmotic potentials in the range of 0 to $-2 \mathrm{MPa}$, primarily due to problems with viscosity and $\mathrm{O}_{2}$ solubility at high PEG concentrations (Vertucci, 1989). Alternatively, desiccators containing silica gel can be used to dry hydrated seeds. This technique provides rapid drying of hydrated seeds to near air-dry moisture contents (Dasgupta and Bewley, 1982).

Control of dehydration rate and degree is also possible by exposing seeds to water vapor above saturated salt solutions in closed containers. At equilibrium, water vapor pressure above a particular salt solution provides a constant relative humidity (Rockland, 1960; Winston and Bates, 1960) that corresponds to a specific atmospheric water potential (Vertucci, 1989). Saturated salt solutions for humidity control are advanta- geous because the atmospheres above them are buffered from changes in vapor pressure since any moisture added to the three-phase (vapor-liquid-solid) system results in dissolution of some solid salts and re-establishment of equilibrium (Rockland, 1960). This equilibrium assures that a constant vapor pressure is maintained above solutions even though seed dehydration contributes water vapor to the surrounding atmoshpere.

Research on seed response to diverse water potentials requires careful attention to continuous control of moisture availability. This paper describes a system for regulating the water potential external to seeds. Water supply was manipulated throughout germination by alternately transferring seeds between liquid (hydration treatments) and vapor (dehydration treatments) moisture environments (Fig. 1).

Hydration phase. Seeds were spread on a strip of Shure-wipe laboratory tissue $(6.5 \times$ $3 \mathrm{~cm}$ ) (Fort Howard Paper, Green Bay, Wis.) that was then placed on one layer of Whatman 1 paper in parafilm-sealed petri dishes (100 $\mathrm{mm}$ in diameter) (Fig. 1A-C). Five milliliters of deionized water was added to each dish, about $2 \mathrm{ml}$ more than enough to completely saturate the filter paper and tissue strip (Fig. 1D). Petri dishes were inclined at an $8^{\circ}$ angle to provide a continual water reservoir at the base of each dish. The filter paper remained saturated during imbibition (i.e., $\psi=0 \mathrm{MPa}$ ) without immersing the seeds. After completion of a hydration phase, the tissue strip and seeds were lifted from the petri dish using forceps and briefly blotted between dry paper towels to remove surface moisture. Seeds were then transferred to the dehydration phase.

Dehydration phase. Seeds were placed in plastic vial lids $(4.7 \times 1 \mathrm{~cm})$ that were floated on the surface of saturated salt solutions (170 $\mathrm{ml}$ ) contained in sealed 250-ml glass jars (Kerr Glass Manufacturing, Los Angeles) (Fig. 1EG).

Temperature control is critical for regulation of humidity above saturated salt solutions. Even at very negative water potentials (- 4 to $-10 \mathrm{MPa}$ ), the relative humidity remains above 90\% (Boyko, 1966). Under these conditions, water vapor pressure is near saturation and a small decrease in temperature $(<2 \mathrm{C})$ causes condensation to occur. Our initial attempts to control humidity above saturated salt solutions in seed germinators and growth chambers proved unsuccessful, because cooling system operation invariably resulted in water condensation onto seeds (and onto the underside of jar lids where it subsequently dripped onto seeds).

An insulated chamber was constructed to facilitate temperature control and prevent condensation (Fig. 2). The chamber consisted of a plywood-framed box (1-cm-thick wood) with interior dimensions of $122 \times 31$ $\times 41 \mathrm{~cm}$ (length $\times$ width $\times$ depth). The chamber was insulated by an air space $(5 \mathrm{~cm}$ on sides and $20 \mathrm{~cm}$ on bottom) covered on all sides with a second layer of plywood and $4 \mathrm{~cm}$ of foam insulation (not shown). The chamber top had an additional $1 \mathrm{~cm}$ of insulation and was removable. Further buffering from temperature fluctuations resulted from placing jars in original packing cases (corrugated cardboard). Air temperatures within jars, the chamber, and in the laboratory were monitored with a five-channel digicator (Omega no. 412B-T-F; Stamford, Conn.) using copper-constantan (type T) thermocouples.

Temperature control was achieved as follows: A thermistor (Waynco no. 03-0076530; Winona, Minn.) placed in the center of the chamber detected a temperature decrease of $\approx 0.1 \mathrm{C}$ (Fig. 2). This decrease signaled an electrical controller (Waynco no. 12-0316) that subsequently relayed electrical current to a $0.2 \mathrm{~A}$ fan (ICM Magnetics no. PWS 2107 FL-M; Rochester, N.H.). Fan operation simultaneously produced and circulated heat throughout the chamber. Fan placement near one end of the chamber resulted in a 


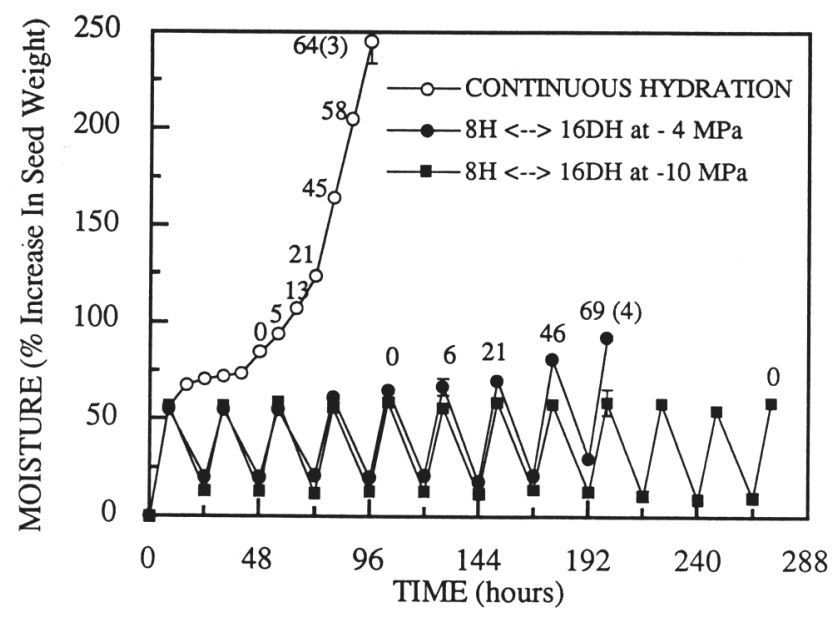

Fig. 3. Moisture uptake and germination of annual bluegrass seeds exposed to continuous or intermittent hydration at 26C. $\mathrm{H}=$ hydration phase hours; $\mathrm{DH}=$ dehydration phase hours; $\langle--\rangle=$ seeds were alternated repeatedly between treatments shown. Numbers associated with data points correspond to total accumulative germination percentages. Maximum standard errors for each treatment are shown for percent moisture (as error bars) and germination (in parentheses).

temperature gradient $(<1 \mathrm{C})$ across the chamber. During experiments, biological effects of this temperature gradient were minimized through randomization of experimental units. By maintaining the chamber temperature above that of the laboratory, the environment external to the chamber provided a continual cooling gradient, eliminating the need for an internal cooling system.

During a typical experiment, the ambient temperature in our laboratory fluctuated between 19 and $23 \mathrm{C}$. Thermocouples randomly placed in jars indicated that temperature precision was $\pm 0.1 \mathrm{C}$. This precision was maintained over a chamber temperature range of 26 to $36 \mathrm{C}$, effectively regulating relative humidities above salt solutions and preventing water vapor condensation. When operating the chamber at $36 \mathrm{C}$ (13 to $17^{\circ}$ above ambient), considerable heat loss occurred if the chamber was opened for more than about 1 min. To reduce this loss, two 3.8-liter glass bottles filled with $36 \mathrm{C}$ water were placed in the chamber when operating at this temperature. At $36 \mathrm{C}$, fan operation was almost continuous. To use the system at higher temperatures, multiple fans (a single, larger fan created an excessive temperature gradient across the chamber), additional insulation, and/or a warmer ambient environment would be required. Similarly, chamber op- eration below $23 \mathrm{C}$ would require that it be placed in an environment with a lower maximum ambient temperature.

Exposure of seeds to controlled hydration-dehydration cycles has been a convenient approach for studying seed response to fluctuating moisture conditions. In particular, this system enabled us to study seed response to variations in rate, degree, timing, and frequency of dehydration episodes initiated following the onset of imbitition. Poa annua (L.) seeds, for example, eventually germinated following exposure to either continuous hydration or cycles of $8 \mathrm{~h}$ hydration alternating with $16 \mathrm{~h}$ dehydration at $-4 \mathrm{Mpa}$ (Fig. 3). However, if dehydration phases occurred at - $10 \mathrm{MPa}$, seeds failed to germinate. In this example, treatment difference would have been impossible to detect if temperature fluctuations had not been precisely controlled. The difference between -4 and - $10 \mathrm{MPa}$ results from a change in relative humidity of only $4 \%$ (97\% and $93 \%$ at $26 \mathrm{C}$, respectively).

The physical characteristics of water movement influence moisture availability in seed germination studies. The imbibition rate is governed by the water potential gradient between seeds and their environment and the hydraulic conductivity of seed tissues and the moisture-supplying medium. If the water potential gradient is reversed during imbibition, full hydration is prevented and water moves out of seeds.

Fluctuating moisture is relevant to the study of seed germination, particularly for small seeds that germinate at or near the soil surface (Hegarty, 1978). The system described here offers the primary advantage of controlling the external physical influences (temperature and external water potential) that interact with seed factors (water conductivity and internal water potential) to determine the rate and degree to which seed hydration or dehydration will occur. Other features that make this system a practical research tool include low cost and simplicity. Relative to growth chambers and seed germinators, the cost of this system was modest (chamber materials and electrical components were purchased for about \$500).

\section{Literature Cited}

Association of Official Seed Analysts. 1989 revision. Rules for testing seeds. J. Seed Technol. 12:1-116.

Boyko, H. 1966. Salinity and aridity: New approaches to old problems. W. Junk, N.V. Publishers, The Hague.

Dasberg, S. and K. Mendel. 1971. The effect of soil water and aeration on seed germination. J. Expt. Bot. 22:992-998.

Dasgupta, J. and J.D. Bewley. 1982. Desiccation of axes of Phaseolus vulgaris during development causes a switch from a development pattern of protein synthesis to a germination pattern. Plant Physiol. 70:1224-1227.

Hadas, A. 1977. A simple laboratory approach to test and estimate seed germination performance under field conditions. Apron J. 69:582-587.

Hegarty, T.W. 1977. Seed and seedling susceptibility to phased moisture stress in soil J. Expt. Bot. 28:659-668.

Hegarty, T.W. 1978. The physiology of seed hydration and dehydration, and the relation between water stress and the control of germination: A review. Plant Cell \& Environ. 1:101-119.

Rockland, L.B. 1960. Saturated salt solutions for static control of relative humidity between 5" and $40^{\circ} \mathrm{C}$. Anal. Chem. 32:1375-1376.

Rose, C.W. 1968. Water transport in soil with a daily temperature wave. I. Theory and experiment. Austral. J. Soil Res. 6:31-44.

Vertucci, C.W. 1989. Kinetics of seed imbibition: Controlling factors and relevance to seedling vigor. p. 93-115. In: P.C. Stanwood and M.B. McDonald. (eds.). Seed moisture. Crop Sci. Soc. Amer. Spec. Publ. 14. Madison, Wis.

Winston, P.W. and D.H. Bates. 1960. Saturated solutions for the control of humidity in biological research. Ecology 41:232-237. 